УДК 330.43:519.24

\title{
С. Ю. Ширнаева
}

ФГАОУ ВО «Самарский Государственный экономический университет», Самара, e-mail: shirnaeva_sy@mail.ru

\section{ЧИСТЫЙ ЭКСПОРТ ТОВАРОВ РОССИЙСКОЙ ФЕДЕРАЦИИ: СТАТИСТИЧЕСКОЕ ИССЛЕДОВАНИЕ И ЭКОНОМЕТРИЧЕСКОЕ МОДЕЛИРОВАНИЕ}

Ключевые слова: чистый экспорт, временной ряд, стационарность, автокорреляция, моделирование.В работе исследуется один из важнейших показателей внешнеторгового оборота чистый экспорт товаров

Российской Федерации, проанализирована динамика данного показателя, свойства и структура его временного ряда, выявлены факторы, оказывающие влияние на чистый экспорт товаров РФ. Применение метода Фостера - Стюарта и метода сравнения средних уровней ряда подтвердило гипотезу о тенденции роста временного ряда чистого экспорта товаров РФ за период с января 1999 г. по апрель 2021 г. Для моделирования чистого экспорта была использована модель авторегрессии и распределенного лага $A D L$. Выбор в пользу модели $A D L$ был сделан в соответствии со следующими причинами: 1) данные модели позволяют учесть влияние на исследуемую зависимую переменную других социально-экономических показателей; 2) для устранения автокорреляции в модель включаются лаговые значения зависимой переменной. В качестве независимых переменных рассматривались показатели, характеризующие различные аспекты социально-экономического развития страны: курсы доллара и евро, индексы цен, показатели рынка труда, торговли, строительства, грузооборота, средние цены на энергоносители и др. По результатам эконометрического моделирования подтверждена высокая степень зависимости чистого экспорта товаров Российской Федерации от курса доллара и цен на энергоресурсы и продукты нефтепереработки.

\section{S. Yu. Shirnaeva}

Samara State University of Economics, Samara, e-mail: shirnaeva_sy@mail.ru

\section{NET EXPORT OF GOODS TO THE RUSSIAN FEDERATION: STATISTICAL RESEARCH AND ECONOMETRIC MODELING}

Keywords: net export, time series, stationarity, autocorrelation, modeling.

The paper examines one of the most important indicators of foreign trade turnover - the net export of goods of the Russian Federation, analyzes the dynamics of this indicator, the properties and structure of its time series, identifies factors that affect the net export of goods of the Russian Federation. The use of the Foster - Stewart method and the method of comparing the average levels of the series confirmed the hypothesis of the growth trend in the time series of net exports of goods of the Russian Federation for the period from January 1999 to April 2021. An autoregressive and distributed lag model ADL was used to simulate net exports. The choice in favor of the ADL model was made in accordance with the following reasons: 1) these models make it possible to take into account the influence of other socio-economic indicators on the investigated dependent variable; 2) to eliminate autocorrelation, the lagged values of the dependent variable are included in the model. Indicators characterizing various aspects of the country's socio-economic development were considered as independent variables: dollar and euro exchange rates, price indices, labor market indicators, trade, construction, freight turnover, average energy prices, etc. Based on the results of econometric modeling, a high degree of dependence of the net export of goods of the Russian Federation on the dollar exchange rate and prices for energy resources and petroleum products has been confirmed.

\section{Введение}

В настоящее время в условиях глобализации внешнеторговый оборот является важнейшим показателем развития Российской экономики и находится в зоне повышенного внимания государства. Правительством РФ принята Государственная программа «Развитие внешнеэкономической деятельности» [1]. Одна из целей програм- мы - укрепление Российской Федерации в мировой экономической системе и повышение эффективности внешнеэкономической деятельности, которая является показателем благосостояния страны, увеличивает объем инвестиций, способствует повышению уровня жизни населения.

Для достижения целей программы необходим регулярный мониторинг или ком- 
плексный статистический анализ внешнеторгового оборота страны и его составляющих, в том числе чистого экспорта. Это в значительной степени определяет актуальность выбранной темы исследования.

Анализ научных работ по статистическому исследованию и моделированию внешнеторгового оборота показал разнообразие подходов к данной проблеме. Авторы используют различные статистические и эконометрические инструменты: кластерный анализ [2], факторный анализ [3], индексный метод [4], гравитационные модели [5], многофакторные регрессионные модели [6], модели $A R I M A, A R M A X$ [7], VEC [8], системы одновременных уравнений [9], и др.

В качестве объектов исследования в работах выступает экспорт, импорт, внешнеторговый оборот в целом. Но такому показателю, как чистый экспорт, уделено крайне мало внимания [9], что также определяет актуальность выбранной темы.

Таким образом, целью работы является статистическое исследование и эконометрическое моделирование одного из показателей внешнеторгового оборота Российской Федерации - чистого экспорта товаров. Задачи исследования: проанализировать динамику данного показателя, свойства и структуру его временного ряда, выявить факторы, оказывающие влияние на чистый экспорт товаров РФ.

\section{Материалы и методы исследования}

Методологическую основу работы составляют статистические и эконометрические методы исследования и моделирования временных рядов, корреляционно-регрессионный анализ, методы оценки качества эконометрических моделей.

Информационной базой исследования являются официальные данные Федеральной службы государственной статистики РФ - краткосрочные экономические показатели Российской Федерации (в том числе показатели экспорта и импорта), представленные в виде временных рядов в помесячной динамике за период с января 1999 г. по апрель 2021 г. [10].

Для реализации поставленных задач в работе использовались пакеты прикладных программ Excel и Gretl.

\section{Результаты исследования и их обсуждение}

Одним из показателей внешнеторгового оборота страны является чистый экспорт товаров или сальдо торгового баланса - разность между экспортом и импортом. Это показатель внешнеторговых сделок страны. Положительное сальдо (превышение экспорта над импортом) означает, что экспортируемые страной товары пользуются спросом на мировом рынке. В этом случае местный производитель имеет преимущества, растут объемы производства, и, как следствие, растет экономика страны в целом. Положительное сальдо может означать также, что имеется переизбыток производимого товара. Отрицательное сальдо (превышение импорта над экспортом) или дефицит торгового баланса означает в стране кроме своих товаров потребляются и импортные товары. Собственные товары в этом случае неконкурентоспособны, а экономика страны является слаборазвитой, что может привести к неспособности расплачиваться с импортерами и девальвации национальной валюты. Положительной стороной дефицита торгового баланса является возможность сдерживания инфляции и поддержка высокого уровня жизни в стране.

По итогам 2019 и 2020 гг. Россия занимала 3-е место после Китая и Германии по величине чистого экспорта товаров (табл. 1). Лидерство Китая объясняется большими объемами экспорта электроники, одежды, текстиля, некоторых видов оборудования и др. Кроме того, в 2020 г. в связи с пандемией коронавируса Китай значительно увеличил экспорт медикаментов. Самый большой в мире отрицательный чистый экспорт имеют Соединенные Штаты Америки, при этом валовый внутренний продукт в этой стране самый большой. Подобный торговый дисбаланс сдерживается свободным рынком посредством корректировок обменного курса. Таким образом, наличие отрицательного сальдо не всегда негативно сказывается на экономической ситуации государства.

Российский чистый экспорт в 2020 г. сократился по сравнению с 2019 г. на 44,46\%, что связано, прежде всего, с падением цен на нефть и пандемией. Впервые за два десятилетия на экспорт энергоносителей (нефть, газ, уголь) пришлось меньше половины общего российского экспорта $(49,6 \%)$ [11]. Одновременно с сокращением экспорта энергоносителей в 2020 г. увеличился экспорт продовольствия, сельскохозяйственного сырья, текстиля, обуви и драгоценных металлов. 
Таблица 1

Чистый экспорт товаров стран мира, млрд долларов США (фрагмент)

\begin{tabular}{|l|c|c|c|}
\hline \multicolumn{1}{|c|}{ Страна } & $\mathbf{2 0 1 9}$ & $\mathbf{2 0 2 0}$ & $\begin{array}{c}\text { Темп } \\
\text { прироста } \\
\mathbf{( \% )}\end{array}$ \\
\hline Китай & 429,62 & 535,01 & 24,53 \\
\hline Германия & 253,37 & 211,43 & $-16,55$ \\
\hline Россия & 165,3 & 91,8 & $-44,46$ \\
\hline Италия & 62,79 & 73,33 & 16,79 \\
\hline Нидерланды & 61,93 & 68,83 & 11,14 \\
\hline Южная Корея & 38,91 & 45,21 & 16,19 \\
\hline Сингапур & 31,36 & 45,22 & 44,20 \\
\hline Мексика & 5,41 & 34,85 & 544,18 \\
\hline Бельгия & $-6,72$ & $-2,98$ & $-55,65$ \\
\hline Канада & $-7,28$ & $-15,88$ & 118,13 \\
\hline Япония & $-15,23$ & 5,88 & $-138,61$ \\
\hline Испания & $-38,27$ & $-17,66$ & $-53,85$ \\
\hline Гонконг & $-42,88$ & $-21,55$ & $-49,74$ \\
\hline Франция & $-86,84$ & $-94,21$ & 8,49 \\
\hline Индия & $-155,63$ & $-92,49$ & $-40,57$ \\
\hline Великобритания & $-224,17$ & $-231,6$ & 3,31 \\
\hline СшА & $-923,22$ & $-975,13$ & 5,62 \\
\hline
\end{tabular}

Источник: расчеты автора на основе [12].

На рис. 1 представлен график временного ряда чистого экспорта $Y$ (млрд долларов
США), рассчитанный как разность экспорта и импорта товаров РФ в соответствующие месяцы. По графику можно предположить неустойчивую тенденцию роста значений чистого экспорта на промежутке с 1999 г. по 2021 г.

Так как графический метод является приближенным, разведочным, то далее использовались более точные статистические методы для проверки наличия тенденции: метод Фостера - Стюарта [13] и метод, основанный на сравнении средних уровней ряда.

По результатам применения метода Фостера-Стюарта гипотеза об отсутствии тренда отвергается на 5\%-ном уровне значимости для всех рассмотренных временных рядов (наблюдаемое значение метода составило 6,60 при критическом значении 1,96). По результатам применения метода сравнения средних уровней ряда получено, что гипотеза о равенстве средних отвергается на 5\%-ном уровне значимости (наблюдаемое значение критерия составило -10,58 при критическом значении 1,65). Применения перечисленных методов подтвердило гипотезу о тенденции роста временного ряда чистого экспорта товаров РФ.

В табл. 2 представлены основные выборочные характеристики и показатели динамики временного ряда чистого экспорта.

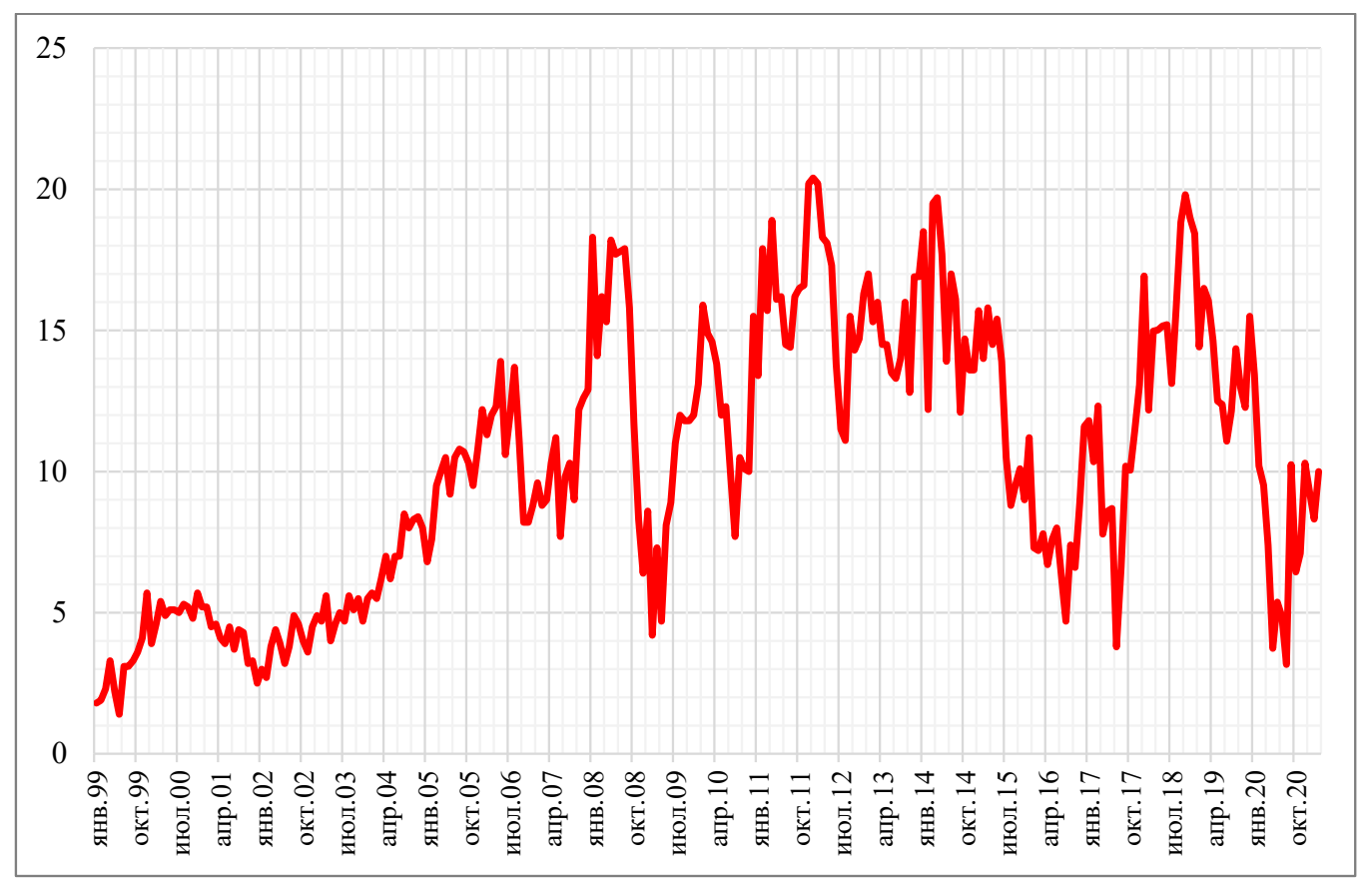

Рис. 1. Динамика чистого экспорта товаров РФ за период с января 1999 г. по апрель 2021 г. 
Выборочные характеристики и показатели динамики временного ряда чистого экспорта товаров РФ $(Y)$

\begin{tabular}{|c|c|c|c|c|c|c|}
\hline & $\begin{array}{c}\text { Средний } \\
\text { уровень } \\
(\overline{\boldsymbol{Y}})\end{array}$ & $\begin{array}{c}\text { Среднее } \\
\text { квадратическое } \\
\text { отклонение }(\boldsymbol{\sigma})\end{array}$ & $\begin{array}{c}\text { Коэффициент } \\
\text { вариации } \\
(\boldsymbol{V})\end{array}$ & $\begin{array}{c}\text { Средний } \\
\text { абсолютный } \\
\text { прирост }(\overline{\boldsymbol{\Delta}})\end{array}$ & $\begin{array}{c}\text { Средний } \\
\text { темп } \\
\text { роста }\left(\overline{\boldsymbol{T}}_{p}\right)\end{array}$ & $\begin{array}{c}\text { Средний темп } \\
\text { прироста } \\
\left(\overline{\boldsymbol{T}}_{\boldsymbol{n}}\right)\end{array}$ \\
\hline$Y$ & 10,25 & 4,79 & 46,70 & 0,03 & 100,64 & 0,64 \\
\hline
\end{tabular}

Источник: расчеты автора.

Таблица 3

Результаты тестирования временного ряда чистого экспорта $(Y)$ на стационарность с помощью расширенного $A D F$-теста

\begin{tabular}{|c|c|c|}
\hline Показатель & $\begin{array}{c}\text { Исходные уровни } \\
\text { (тест с константой и трендом) }\end{array}$ & $\begin{array}{c}\text { Первые разности } \\
\text { (тест с константой) }\end{array}$ \\
\hline$Y$ & $-2,44(0,1294)$ & $-4,84(0,0000)$ \\
\hline
\end{tabular}

Источник: расчеты автора (в скобках указаны соответствующие $p$-значения).

Коэффициент вариации превышает 33\%, что говорит о неоднородности совокупности и может быть связано с наличием сезонных колебаний в структуре временного ряда исследуемого показателя.

По результатам проведенных расчетов получено, что средний темп роста $\left(\bar{T}_{p}\right)$ для показателя $Y$ составляет $100,64 \%$. Таким образом, величина чистого экспорта в рассматриваемом периоде ежемесячно увеличивается в среднем на 0,64\%.

При исследовании на стационарность с помощью расширенного теста Дики-Фуллера (расширенного $A D F$-теста) получено, что временной ряд чистого экспорта является стационарным в первых разностях, то есть является интегрированным первого порядка (табл. 3).

Вывод о коррелированности уровней временного ряда чистого экспорта был сделан на основании анализа графиков автокорреляционной $(A K \Phi)$ и частной автокорреляционной (ЧАКФ) функций для данного ряда (рис. 2). Два первых значимых коэффициента автокорреляции на графике частной автокорреляционной функции позволяют предположить, что анализируемый временной ряд подчиняется автокорреляционной схеме второго порядка $A R(2)$.

Значимый коэффициент автокорреляции 12-го порядка означает наличие сезонной компоненты в структуре ряда (сезонная компонента мультипликативная, так как сезонные колебания имеют непостоянную амплитуду (см. рис. 1)). Для целей исследования сезонная компонента была устранена.

Учитывая выявленные ранее свойства, для моделирования чистого экспорта товаров РФ была использована модель авторегрессии и распределенного лага $A D L$. В данном случае использовалась модель $A D L(p, r, s)$, где $p$ - число лагов зависимой переменной, $r$ - число лагов независимых переменных, $s$ - число независимых переменных [14]. Выбор в пользу модели $A D L$ был сделан в соответствии со следующими причинами:

- данные модели позволяют учесть влияние на исследуемую зависимую переменную других социально-экономических показателей;

- для устранения автокорреляции в модель включаются лаговые значения зависимой переменной.

В качестве независимых переменных рассматривались показатели, характеризующие различные аспекты социально-экономического развития страны: курсы доллара и евро, индексы цен, показатели рынка труда, торговли, строительства, грузооборота, средние цены на энергоносители и др. (всего 20 показателей).

Временные ряды всех показателей исследовались на наличие сезонной компоненты (которая была устранена в случае обнаружения) и на стационарность. Для моделирования использовались только переменные, имеющие с зависимой переменной $Y$ одинаковый порядок интегрированности. 

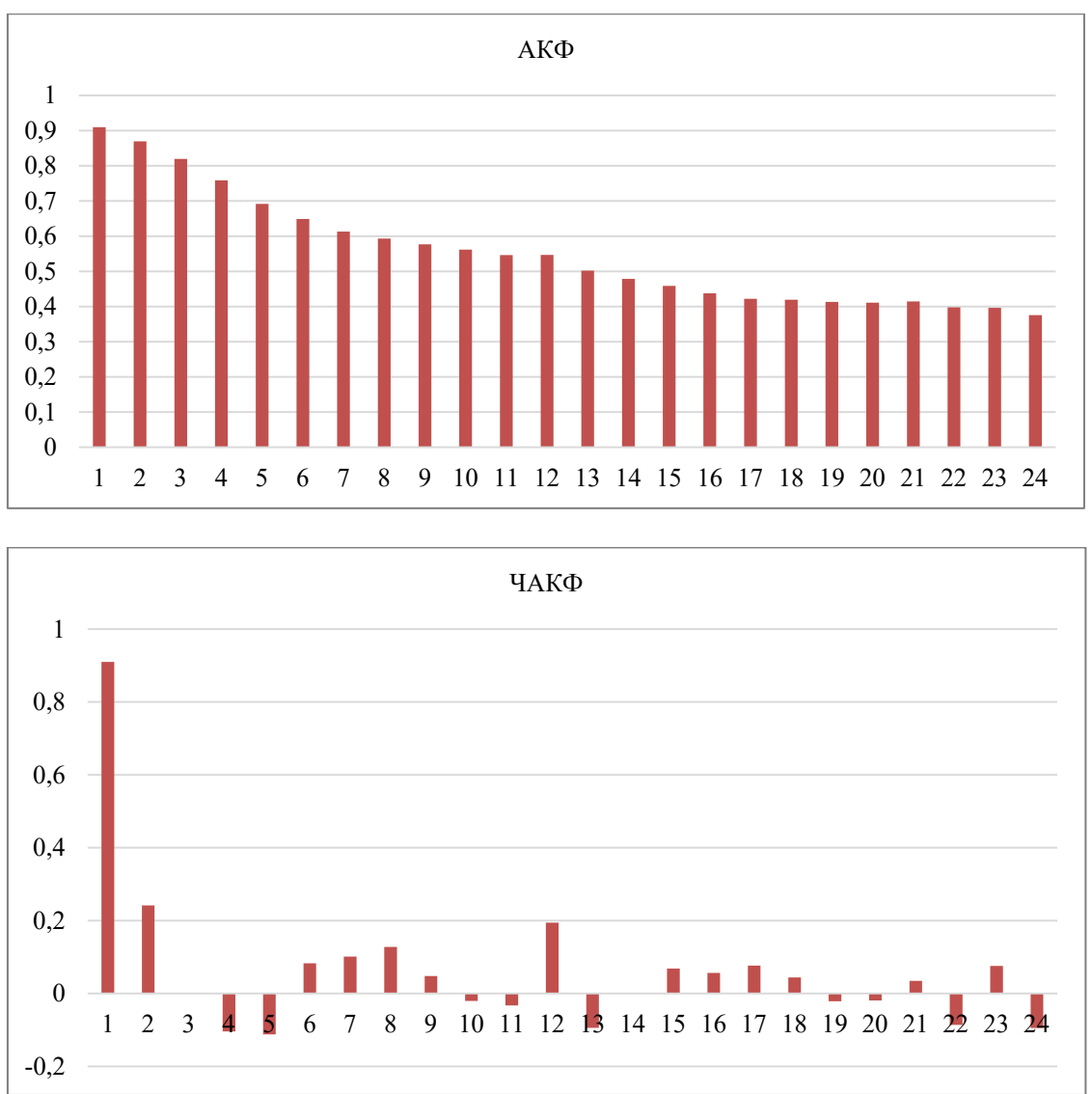

Рис.2. Графики автокорреляциионной (АКФ) и частной автокоррелячионной (ЧАКФ) функиий временного ряда чистого экспорта товаров РФ (Y)

Таблица 4

Результаты оценки параметров модели (1)

\begin{tabular}{|c|c|c|c|}
\hline & Коэффициент & Стандартная ошибка & Р-значение \\
\hline const & 0,57 & 4,77 & 0,9055 \\
\hline$Y_{t-1}$ & 0,58 & 0,06 & $<0,0001$ \\
\hline$Y_{t-2}$ & 0,34 & 0,06 & $<0,0001$ \\
\hline$X_{2}$ & 0,03 & 0,01 & 0,0015 \\
\hline$X_{14}$ & $-0,52$ & 0,111 & 0,0485 \\
\hline$X_{17}$ & 0,0003 & 0,00 & $<0,0001$ \\
\hline$X_{18}$ & 0,002 & 0,00 & 0,0365 \\
\hline$R^{2}$ & \multicolumn{3}{|c|}{0,8844} \\
\hline
\end{tabular}

Источник: расчеты автора.

Результаты моделирования чистого экспорта показали, что наилучшими свойствами обладает модель $A D L(2,1,4)$ следующего вида $(t=1 ; 268)$ :

$$
\hat{Y}_{t}=0,57+0,58 Y_{t-1}+0,34 Y_{t-2}+0,03 X_{2, t}-0,52 X_{14, t}+0,0003 X_{17, t}+0,002 X_{18, t},
$$

где $X_{2}$ - коммерческий грузооборот транспорта (млрд тонно-км),

$X_{14}-$ уровень безработицы в возрасте $15-72$ лет (\%),

$X_{17}$ - средние цены производителей на нефть сырую (рублей за тонну),

$X_{18}$ - средние цены производителей на уголь (рублей за тонну).

Значения критериев качества модели (1) представлены в табл. 4. 
Построенная модель обладает хорошей объясняющей способностью, так как коэффициент детерминации $R^{2}$ составил $88,4 \%$. Оценки параметров модели (кроме константы) статистически значимы на 5\%-ном уровне значимости.

Остатки модели (1) обладают следующими свойствами:

- остатки стационарны по результатам теста Дики-Фуллера с константой $-16,59$ $(0,000)$;

- остатки не коррелированы по результатам $Q$-теста Льюинга-Бокса $Q=11,25$ $(0,3387)$.

Таким образом, на величину чистого экспорта товаров РФ за период с января 1999 г. по апрель 2021 г. помимо собственных значений с лагом в 1 и 2 месяца, оказывают влияние грузооборот транспорта, состояние рынка труда и средние цены на энергоресурсы и продукты нефтепереработки

\section{Заключение}

Российский внешнеторговый оборот, его структура и динамика существенным образом зависит от мировой экономической и политической ситуации, что нашло подтверждение в работе при построении эконометрической модели чистого экспорта РФ. По результатам эконометрического моделирования на рассматриваемом временном промежутке остается высокая степень зависимости чистого экспорта нашей страны от цен на энергоресурсы и продукты нефтепереработки.

По результатам проведенного исследования, чистый экспорт России, не смотря на современную санкционную политику, пандемию, существенное сокращение в 2020 г., характеризуется положительной динамикой развития. Свойства временного ряда чистого экспорта (структура, порядок интегрированности и др.) схожи со свой- ствами временных рядов показателей экспорта и импорта РФ [15].

В сложившихся условиях мировой экономической нестабильности наиболее эффективной для государства становится политика импортозамещения. Это способствует повышению конкурентоспособности отечественных производителей (особенно в сфере сельского хозяйства), стабилизирует ситуацию на рынке труда за счет появления новых рабочих мест, увеличивает объемы производства и укрепляет актуализированную пандемией продовольственную безопасность страны.

В экспортной политике наиболее перспективной является увеличение доли высокотехнологичной продукции (например, перестройка автомобильной промышленности с переориентацией на экспорт [16]).

В целом, для увеличения объема внешнеторгового оборота, среди необходимых государственных мер можно выделить: привлечение иностранных технологий и инвестиций, совершенствование таможенного законодательства, укрепление курса рубля по отношению к доллару и евро.

Исследование может быть продолжено с целью усовершенствования построенной эконометрической модели, уточнения набора независимых переменных. Также перспективным направлением дальнейшего исследования представляется применение других методов моделирования показателей внешнеторгового оборота (например, построение модели $G A R C H$ (обобщённая авторегрессионная условная гетероскедастичность) для описания временного ряда чистого экспорта товаров РФ).

В дальнейшем, при наличии соответствующей статистической информации, интересным представляется исследование влияния пандемии коронавируса на свойства и динамику временного ряда чистого экспорта товаров Российской Федерации.

\section{Библиографический список}

1. Развитие внешнеэкономической деятельности. Постановление Правительства Российской Федерации от 28.03.2019 № 349. Портал Госпрограмм РФ [Электронный ресурс]. - URL: https://programs.gov. ru/Portal/programs/subActionsList?gpId=27\&pgpId=35B2AD11-15E1-43FF-9C07-A1FE9A742E80 (дата обращения: 07.06.2021).

2. Оганнисян Э.Г., Шаталова А.С. Классификация стран мира по показателям экспортно-импортных операций // Фундаментальные исследования. 2019. № 1. С. 46-52. 
3. Глебкова И.Ю., Качанова Н.Н. Факторный анализ показателей внешней торговли // Евразийский союз ученых. 2015. № 2-1 (11). С. 56-59.

4. Ускова Т.В., Асанович В.Я., Дедков С.М., Селименков Р.Ю. Внешнеэкономическая деятельность регионов СЗФО и республики Беларусь: состояние и методологические аспекты моделирования // Экономические и социальные перемены: факты, тенденции, прогноз. 2010. № 4 (12). С. 118-130.

5. Keogh G.A Gravity Model Analysis of Irish Merchandise Goods Exports under Brexit // Journal of the statistical and social inquiry society of Ireland. 2019. Vol. 48. P. 41-70.

6. Лапин А.В. Построение эконометрических моделей и анализ факторов экспорта и импорта СанктПетербурга // Молодой ученый. 2016. № 13. С. 44-46. [Электронный ресурc]. URL: https://moluch.ru/ archive/117/32290/ (дата обращения: 09.06.2021).

7. Го Х. Прогнозирование динамики логистических факторов в развитии внешнеторгового товарооборота России и Китая. // Логистика и управление цепями поставок: сборник научных трудов. СанктПетербург, 2019. С. 35-38.

8. Суханова Е.И., Ширнаева С.Ю. Различные подходы к моделированию и прогнозированию макроэкономических процессов // Фундаментальные исследования. 2015. № 12-2. С. 406-411.

9. Суханова Е.И., Ширнаева С.Ю. Типологизация показателей, отражающих стабилизационные процессы экономики России, по критериям устойчивости // Вестник Самарского государственного экономического университета. 2012. № 5 (91). С. 103-109.

10. Краткосрочные экономические показатели Российской Федерации. М., 2020. [Электронный реcypc]. URL: https://gks.ru/compendium/document/50802 (дата обращения: 1.07.2021).

11. Как изменилась за год торговля России с другими странами. Главное. РБК. [Электронный ресурс]. URL: https://www.rbc.ru/economics/15/02/2021/6028f9c79a794754fdb4362ehttps://www.rbc.ru/economics/15/ 02/2021/6028f9c79a794754fdb4362e (дата обращения: 06.07.2021).

12. Базы данных торговли по странам (экспорт и импорт). TrendEconomy. [Электронный ресурc]. URL: https://trendeconomy.ru/trade (дата обращения: 09.06.2021).

13. Фахрова Д.В. Анализ наличия тренда в уровнях ряда динамики по методу Фостера-Стюарта // Инновация в АПК: стимулы и барьеры: сборник статей по материалам международной научно-практической конференции. (Рязань, 21 июня 2017 г.). М.: ООО Издательство: «Научный консультант», 2017. С. 358-363.

14. Калугин Т.Р., Ким А.К., Петрусевич Д.А. Анализ моделей $\operatorname{ADL}(\mathrm{p}, \mathrm{q})$, используемых для описания связей между временными рядами // Российский технологический журнал. 2020. № 8 (2). С. 7-22. [Электронный pecypc]. URL: https://www.rtj-mirea.ru/jour/article/view/207 (дата обращения: 25.06.2021).

15. Ширнаева С.Ю. Эконометрическое моделирование и прогнозирование показателей экспорта товаров Российской Федерации // Фундаментальные исследования. 2020. № 6. С. 172-177.

16. Итоги внешнеэкономической деятельности Российской Федерации в 2019 году. [Электронный pecypc]. URL: https://www.economy.gov.ru/material/dokumenty/itogi_vneshneekonomicheskoy_deyatelnosti_ rossiyskoy_federacii_v_2019_godu.html (дата обращения: 01.06.2021). 